\title{
Vikram Kumar
}

With a dash of tech savvy and a dose of medical wisdom, Vikram Kumar is trying to solve intractable problems in public healthand all at the ripe old age of 30 .

In rural Zambia, people are often on the move, changing homes, schools and clinics with every move. Their medical records are rarely, if ever, maintained by hospitals.

But since last year, 60,000 HIV-positive Zambians in Lusaka district have carried their entire medical histories on plastic 'smart cards'-like those used at gas stations or office cafeterias in the US or Europe. When a doctor swipes the card at a clinic's computer, a program pulls up the person's entire medical record, helping the doctor decide on the best course of treatment. The transaction is then recorded in a central database that can later be used to track outcomes and order new drugs.

This creative system, dubbed SmartCare, was designed in consultation with Zambia's Ministry of Health and the US Centers for Disease Control and Prevention (CDC) by Dimagi, a tiny Boston-based informatics company.

A clinician, programmer, entrepreneur and do-gooder, Vikram Kumar has turned Dimagi into a one-stop technical shop for public health experts who use data management to save lives - and this before his academic career has even begun.

Just 30, Kumar is finishing a residency in clinical pathology at Boston's Brigham and Women's Hospital, where he is trying to combine patient records with the hospital's architectural plans in order to track the spread of hospital-acquired infections.

"He has a much broader appreciation than most people for the texture of human life," says Sandy Pentland, chief of the Massachusetts Institute of Technology (MIT)'s Media Lab. "Partly it comes from his IndianAmerican perspective, but also he's done work on rural health care in Africa and India while being at a high-tech medical institution."

Born in Buffalo, New York, Kumar moved to New Delhi at age ten. Hoping to bring his children closer to their Indian roots, his father had abandoned a neurosurgery practice and instead took on sundry projects, from selling leather to helping start a hospital. That spirit of adventure inspired Kumar, as did the swamis who often stayed with his family.

"You become more thoughtful, living with people who have renounced everything," says Kumar. "They are constantly pursuing knowledge, bettering themselves, giving themselves. My father and mother are the same. That gave me a passion to do this work."

Kumar learned to write code at the prestigious Indian Institute of Technology in New Delhi, where he spent a year studying textile engineering. Anxious to pursue more philanthropic ends, he transferred to Columbia University in 1995 and began studying medicine, business and engineering. In 1999, he enrolled in Harvard University's Health Sciences and Technology program, offered jointly with MIT. It was there that he met Dimagi co-founders Tarjei Mikkelsen, a medical software engineer, and Vishwanath Anantraman, who had been a physician in rural India.

Around this time Kumar also attended a public health conference where speakers discussed the benefits of wiring Africa for the Internet, but didn't address where the money would come from or whether people could benefit more quickly from simpler systems.

“The idea that you needed a huge infrastructure that didn't yet exist struck me as excessive," says Kumar, who figured that small-scale interventions using already-available products made more sense.

At the media lab, he developed DiaBetNet, a guessing game designed to help children with type 1 diabetes with the arduous task of tracking their diets and blood sugar. Named by Business Week magazine as one of the top ten designs of the 1990s, DiaBetNet never went beyond academic use, but embodied a focus on individual user experience that has become Kumar's signature.

On a wet winter day in Boston, Kumar is the picture of a technovisionary humanitarian, wearing a lime-green sweater and red-framed glasses and jumping wildly from topic to topic, waving his hands excitedly. But he is disarmingly modest about the limits of his technology. "If it becomes clear the problem is about something else than the software we can write, we won't even do it," he says.

Kumar is quick to admit to his earlier mistakes, when Dimagi concentrated more on user-friendly technology than on making it sustainable in a low-tech environment. The company's first program, which gave handheld computers to nurses in rural India, folded after the Indian government cut its funding and the media lab's Asian office closed. A project for ensuring the confidentiality of HIV tests in South Africa failed because people who took the tests didn't want to know the results.

But when a Fortune 500 executive dismissed Dimagi as yet another flyby-night graduate school project, Kumar and his colleagues came back to the company with renewed vigor. "There's no better way to get a guy like me to do something than to tell him he can't do it," Kumar says.

Kumar has cut back on writing code to concentrate on negotiating grants and finding partners with long-term plans and local expertise.

"Initially they were working in a high-tech, let's-go-in-and-try kind of way," says Hamish Fraser, director of informatics and telemedicine at Partners in Health, a Boston-based nonprofit that provides developing world health care. "Now they're developing long-term relationships, as in Zambia."

One of those relationships is with Stephen Rahaim, a program officer at the Program for Appropriate Technology in Health, a Seattlebased nonprofit health organization. After meeting Kumar over lunch, Rahaim immediately agreed to partner with Dimagi on an application to implement the US Agency for International Development's AIDS programs.

"It was a quick lunch, too," says Rahaim, who added that he usually takes months to negotiate such partnerships. "He's very open and engaging, speaks with a huge smile, and doesn't come with any assumptions about how grandiose the solution needs to be."

In Zambia, the Ministry of Health has officially adopted the record-keeping framework designed by Dimagi to accompany SmartCare as a national standard. The ministry plans to implement the program in every clinic that distributes antiretroviral drugs. Kumar hopes the system will be adapted to other countries and diseases. Eventually, he says, he'd like to open a personalized medicine clinic, but has no intention of leaving Dimagi or defining his roles in life more narrowly.

"At the medical school, I'm the media lab guy. At the media lab, I'm the medical guy," he says. "I feel that I need to be slightly outside. You can't fit all the pieces of the puzzle together if you're inside the puzzle."

Brandon Keim, New York

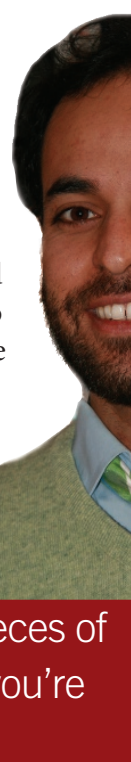

